\title{
Structural and Magnetic Properties of Spinel Nickel-Cobalt Ferrite Nanoparticles Substituted by Dysprosium Cation Synthesized by Hydrothermal Method
}

\author{
S. Balideh, A. Aavazpour*, G. Rezaei and A. Nikzad \\ Department of Physics, University of Yasouj, Yasouj, 75918-74934, Iran \\ Received: 26.12.2020 \& Accepted: 21.04.2021
}

Doi: $10.12693 /$ APhysPolA.140.14

*e-mail: avazpour@yu.ac.ir

\begin{abstract}
Dysprosium-doped nickel-cobalt ferrite nanoparticle samples of the chemical formula $\mathrm{Ni}_{0.3} \mathrm{Co}_{0.7} \mathrm{Dy}_{x} \mathrm{Fe}_{2-x} \mathrm{O}_{4}(x=0.0,0.02,0.04,0.06,0.08$, and 0.1$)$ were synthesized by the hydrothermal method followed by an annealing treatment and using $\mathrm{NaOH}$ as a solvent. The synthesized samples were annealed at $150^{\circ}$ for $7 \mathrm{~h}$. The influence of Dy doping on structural, morphological, electrical and magnetic properties was studied. The structure, size, morphology, and magnetic properties of synthesized compounds were investigated by using X-ray diffraction, the Fourier transform infrared spectroscopy, the field emission scanning electron microscopy, an energy dispersive spectrometer and a vibrating sample magnetometer (VSM). The formation of a ferrite phase was confirmed by X-ray diffraction. An increase in the average crystallite and grain size has been observed with an increase in Dy doping. The Fourier transform infrared spectra showed two characteristic strong absorption bands at 500-600 $\mathrm{cm}^{-1}$. The field emission scanning electron microscopy analysis showed a regular spherical shape and particles with an average size ranging from $45 \mathrm{~nm}$ to $60 \mathrm{~nm}$. By studying the energy dispersive spectrometer analysis patterns, the existence of constituent elements, $\mathrm{Co}, \mathrm{Ni}, \mathrm{Fe}$, and Dy, was verified with the proportion very close to the stoichiometry of the chemical formula. Magnetic measurements confirmed the typical magnetic behavior of spinel ferrite nanoparticles and magnetic hysteresis behavior was improved as compared to earlier reports.
\end{abstract}

topics: nanoferrite, nickel-cobalt, dysprosium, magnetic properties

\section{Introduction}

Intensive research on the synthesis and application of nanomaterials has been carried out for their unique physical and chemical properties [1]. Understanding these properties is important. During the past three decades, nanostructured spinel ferrite materials have become important because of their excellent features [1,2]. Generally, ferrites can be divided into four subgroups: (i) spinel, (ii) hexagonal, (iii) garnet, and (iv) perovskite-type ferrites [3-5]. Spinel ferrites, $\mathrm{MFe}_{2} \mathrm{O}_{4}$ ( $\mathrm{M}$ denotes some divalent metals such as $\mathrm{Co}, \mathrm{Ni}, \mathrm{Mn}, \mathrm{Cu}, \mathrm{Zn}$, and $\mathrm{Mg}$ ), are a technologically important group of materials due to their enhanced optical, magnetic, and electrical properties [6]. Some of the outstanding specifications of spinel ferrites are high saturation magnetization, high permeability, and a remarkably high electrical resistivity at high frequency [7-9]. These specifications are useful for a variety of applications including magnetic data storage, microwave absorbing materials, targeted release of drugs, water purification, ferrofluids, high frequency devices, magnetic refrigerators, new pigments, miniaturized magnetoelectric sensors, 3D transformers, inductors, high frequency components, and biotechnological applications [7, 10-13].

The chemical expression of a typical ferrite material with a spinel structure is $\left(\mathrm{A}^{2+}\right)\left[\mathrm{B}_{2}^{3+}\right] \mathrm{O}_{4}$, where $\mathrm{A}$ and $\mathrm{B}$ are cations in tetrahedral and octahedral sites, respectively [2]. The usual formula of a spinel ferrite expressed as $\left(\mathrm{M}_{1-i}^{2+} \mathrm{Fe}_{i}^{3+}\right)\left[\mathrm{M}_{i}^{2+} \mathrm{Fe}_{2+i}^{3+}\right] \mathrm{O}_{4}$, where $i$ is the degree of inversion, showing the percentage of A sites occupied by $\mathrm{Fe}^{3+}$ cations [2]. The cation distribution has an important effect on the microstructure and magnetic properties of spinel ferrite nanoparticles [2]. Two fundamental factors responsible for the preference of nanomaterials over the bulk ones are: (i) the surface effects and (ii) the quantum effects. These factors affect the chemical reactivity of materials and physical properties, such as mechanical, optical, electrical, and magnetic properties $[1,2]$.

Fabrication and investigation of the structural and physical properties of mixed-structured ferrites such as $\mathrm{Ni}-\mathrm{Zn}, \mathrm{Ni}-\mathrm{Mg}$ and $\mathrm{Ni}-\mathrm{Co}$ ferrites have been announced [2]. The $\mathrm{Ni}-\mathrm{Co}$ ferrite is highly resistive and magnetostrictive [10]. Rare earth-substituted 
nanoferrites are useful for various applications [14]. The doping of a small amount of rare-earth ions like $\mathrm{Gd}$, $\mathrm{La}, \mathrm{Ce}$, and Dy for $\mathrm{Fe}^{3+}$ in spinel ferrites results in a satisfactory character in the electrical, magnetic and structural properties depending upon the type and amount of the used rare-earth element $[4,14]$. Changes in the properties of ferrites are related to the segregation of secondary phases in grain boundaries, so it is important to control rareearth solubility in ferrites $[10,15]$. The substitution of the rare-earth ion into the spinel structure shows a structural distortion inducing strain in the sample with a significant change in the electrical and magnetic properties [10]. The substitution of rareearth ions into the ferrite led to the replacement of $\mathrm{Fe}^{3+}$ by rare-earth ions and limited solubility in the spinel lattice due to their large ionic radii [14]. The difference in the rare-earth ionic radii will lead to micro strain which may cause a deformation of the spinel structure [14].

Kadam et al. [10] synthesized a Dy-doped Ni-Co ferrite with the formula $\mathrm{Ni}_{0.8} \mathrm{Co}_{0.2} \mathrm{Fe}_{2-x} \mathrm{Dy}_{x} \mathrm{O}_{4}$ $(0 \leq x \leq 0.1$ in a period of 0.025). They found that the substitution of $\mathrm{Fe}^{3+}$ with $\mathrm{Dy}^{3+}$ decreased the value of both $M_{s}$ and $H_{c}$. Hydrothermal processing, chemical co-precipitation, high energy milling, and the sol-gel method are typical methods of preparing nanostructured ferrites. Complex processes, expensive precursors and low production rates are common problems in many of these techniques $[12,16-18]$. The hydrothermal route is a promising method for the preparation of nanoferrites that is based on the ability of water to hydrolyze and dehydrate metal salts at elevated pressures and temperatures [1]. Because of high resistance, ferromagnetic nature and the maximum saturation magnetization of $\mathrm{Ni}_{0.3} \mathrm{Co}_{0.7} \mathrm{Fe}_{2} \mathrm{O}_{4}$ [19], this combination was chosen as the parent. From [20], erbium lanthanidesubstituted nickel-cobalt spinel ferrite nanoparticles showed the improvement of saturation magnetization of the nanoferrite. In order to improve the physical properties of the mentioned base, Dy lanthanide was chosen as a substitution. Instead of the co-precipitation route of [21] or the simple ceramic method of [10], we prepared a series of Dysubstituted nickel-cobalt ferrite nanoparticles with the formula $\mathrm{Ni}_{0.3} \mathrm{Co}_{0.7} \mathrm{Dy}_{x} \mathrm{Fe}_{2-x} \mathrm{O}_{4}(0 \leq x \leq 0.1$ in a period of 0.02$)$ via the hydrothermal method and investigated the impact of the $\mathrm{Dy}^{3+}$ ion concentration on the structural and magnetic properties of this compound.

\section{Experimental procedure}

The $\mathrm{Ni}_{0.3} \mathrm{Co}_{0.7} \mathrm{Dy}_{x} \mathrm{Fe}_{2-x} \mathrm{O}_{4}(x=0.0,0.02,0.04$, $0.06,0.08$, and 0.1 ) ferrites were prepared using the hydrothermal route. Nickel-cobalt ferrite samples were prepared by combining iron chloride hexahydrate $\mathrm{FeCl}_{3} \cdot 6 \mathrm{H}_{2} \mathrm{O}, \mathrm{NiCl}_{3}, \mathrm{CoCl}_{2}$ and $\mathrm{DyCl}_{2}$ (all from MERK Company without further impurity) as starting materials in a strong alkaline medium by using $\mathrm{NaOH}$ as a solvent and autoclaving. Stoichiometric amounts of $\mathrm{FeCl}_{3} \cdot 6 \mathrm{H}_{2} \mathrm{O}, \mathrm{NiCl}_{3}, \mathrm{CoCl}_{2}$ and $\mathrm{NaOH}$ were mixed. To obtain the homogeneous solution, the mixture was slowly stirred and simultaneously heated and then the $\mathrm{NaOH}$ solution was added drop by drop to ensure that the materials have been uniformly mixed. After mixing properly, the dark brown solution was formed and the prepared suspension was left aside for $24 \mathrm{~h}$ to settle the material and remove the salt. Subsequently, the material was twice centrifuged and washed with distilled water to reach a pure material. This precipitate was transferred into a Teflon stainless-steel autoclave and heated for $7 \mathrm{~h}$ at $150^{\circ} \mathrm{C}$. After this duration, the precipitate was poured into a beaker and dried at $100^{\circ} \mathrm{C}$ for $10 \mathrm{~h}$ by using an oven. Finally, the dried product was carefully milled and placed in an oven for $7 \mathrm{~h}$ at $150^{\circ} \mathrm{C}$.

\subsection{Characterization}

The structure and phase composition of the nickel-cobalt ferrite nanoparticles were analyzed by X-ray diffraction (XRD; PHILIPS MPD-XPERT) using $\mathrm{Cu} K_{\alpha}$ radiation $(\lambda=0.15406 \mathrm{~nm})$ operated at $40 \mathrm{kV}$ and $30 \mathrm{~mA}$ with a scan step size of $0.05^{\circ} / \mathrm{s}$ in the range of $20-70^{\circ}$. The Fourier transform infrared spectra analysis was carried out for all the obtained samples to determine chemical bonds which were recorded using a Nicolet 100IR spectrometer in the wave number range of $400-4000 \mathrm{~cm}^{-1}$. In order to determine the morphology and chemistry of nanosized particles, the field emission scanning electron microscopy (FESEM; Model Mira3XMU, TESCAN) was linked with an energy dispersive X-ray analysis (EDS). A vibrating sample magnetometer (VSM; Meghnatis Daghigh Kavir Co., Iran) with an applied field of up to $10 \mathrm{kOe}$, at room temperature, was used to measure the magnetic properties of the prepared samples.

\section{Results and discussion}

\subsection{XRD analysis}

The X-ray diffraction patterns of the series of Dysubstituted $\mathrm{Ni}-\mathrm{Co}$ ferrite $\mathrm{Ni}_{0.3} \mathrm{Co}_{0.7} \mathrm{Dy}_{x} \mathrm{Fe}_{2-x} \mathrm{O}_{4}$ $(x=0.0,0.02,0.04,0.06,0.08$, and 0.1$)$ nanoferrite systems are shown in Fig. 1.

The nickel-cobalt spinel ferrite phase was characterized by the reflection peaks from the planes (111), (220), (311), (222), (400), (422), (511), (440), (620), and (440). The crystal structure and phase recognition of all the prepared samples were determined using the XRD technique. The diffraction peaks of the samples show the existence of a singlephase spinel ferrite crystal structure with no traces of intermediate and impurity phases. All peaks were consistent with the spinel ferrite phase according to the JCPDS file No. 00-001-1121 $\left(\mathrm{CoFe}_{2} \mathrm{O}_{4}\right)$, 


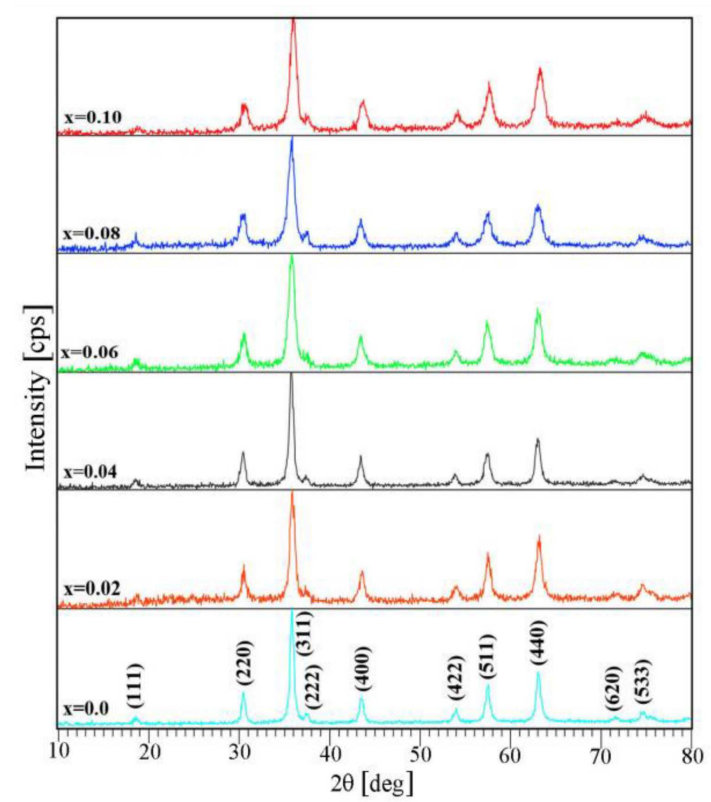

Fig. 1. X-ray diffraction patterns of the $\mathrm{Ni}_{0 .} \mathrm{Co}_{0.7} \mathrm{Dy}_{x} \mathrm{Fe}_{2-x} \mathrm{O}_{4}$ nanoferrite for all specimens.

TABLE I

XRD data consist of crystallites size and lattice parameters of the $\mathrm{Ni}_{0.3} \mathrm{Co}_{0.7} \mathrm{Dy}_{x} \mathrm{Fe}_{2-x} \mathrm{O}_{4}$ nanoferrite.

\begin{tabular}{c|c|c}
\hline \hline Samples & $\begin{array}{c}\text { Crystallite } \\
\text { size } \\
\pm 0.1[\mathrm{~nm}]\end{array}$ & $\begin{array}{c}\text { Lattice } \\
\text { parameter } \\
\pm 0.001[\AA]\end{array}$ \\
\hline $\mathrm{Ni}_{0.3} \mathrm{Co}_{0.7} \mathrm{Fe}_{2} \mathrm{O}_{4}$ & 22.4 & 8.384 \\
$\mathrm{Ni}_{0.3} \mathrm{Co}_{0.7} \mathrm{Dy}_{0.02} \mathrm{Fe}_{1.98} \mathrm{O}_{4}$ & 23.6 & 8.392 \\
$\mathrm{Ni}_{0.3} \mathrm{Co}_{0.7} \mathrm{Dy}_{0.04} \mathrm{Fe}_{1.96} \mathrm{O}_{4}$ & 24.0 & 8.398 \\
$\mathrm{Ni}_{0.3} \mathrm{Co}_{0.7} \mathrm{Dy}_{0.06} \mathrm{Fe}_{1.94} \mathrm{O}_{4}$ & 24.8 & 8.402 \\
$\mathrm{Ni}_{0.3} \mathrm{Co}_{0.7} \mathrm{Dy}_{0.08} \mathrm{Fe}_{1.92} \mathrm{O}_{4}$ & 25.4 & 8.406 \\
$\mathrm{Ni}_{0.3} \mathrm{Co}_{0.7} \mathrm{Dy}_{0.10} \mathrm{Fe}_{1.90} \mathrm{O}_{4}$ & 26.4 & 8.408
\end{tabular}

00-003-0875 $\left(\mathrm{NiFe}_{2} \mathrm{O}_{4}\right)$ which approved the compositions of single phase $\mathrm{Ni}-\mathrm{Co}-\mathrm{Dy}$ nanoferrites. In contrast to the result of [10], no significant change in intensity of (311) pick was observed in our samples with increasing Dy content. XRD data shown in Table I provided the average crystallite sizes $(D)$ and lattice parameters $(a=b=c)$ for all specimens.

It can be seen that the crystallite sizes (obtained by the Scherrer formula) increased by increasing the Dy cation content from $22.4 \mathrm{~nm}$ for $x=0.0$ to $26.4 \mathrm{~nm}$ for $x=0.1$ compounds. Also, the lattice parameters increased from $8.384 \AA$ to $8.408 \AA$ with increasing substitution. Since the ionic radius of $\mathrm{Fe}^{3+}$ ions $(0.64 \AA)$ is smaller than the ionic radius of $\mathrm{Dy}^{3+}$ cations $(0.99 \AA)$, iron ions were substituted by dysprosium ions and the average crystallite sizes and lattice parameters increased. This increase is not consistent with the decreasing trend in erbium substituted samples of reference [20]. It may depend on smaller ionic radius of $\mathrm{Dy}^{3+}$ as compared to the erbium ion.
The results reported in Table I are in qualitative agreement with the results of [10], but are better than them, quantitatively.

\subsection{FTIR analysis}

The FTIR spectra of $\mathrm{Ni}_{0.3} \mathrm{Co}_{0.7} \mathrm{Dy}_{x} \mathrm{Fe}_{2-x} \mathrm{O}_{4}(x=$ $0.0,0.02,0.04,0.06,0.08$, and 0.1 ) nanoferrite samples recorded in the range of $400-4000 \mathrm{~cm}^{-1}$ are shown in Fig. 2.

It has been reported that the IR bands of solids are usually assigned to vibration of ions in the crystal lattice [1]. In all the spectra, regardless of the Dy substitution content $x$, two strong absorption bands are visible which can be assigned to metal-oxygen complex vibrations. The higher frequency band $500-600 \mathrm{~cm}^{-1}$ corresponds to intrinsic stretching vibrations of the metal at the tetrahedral site and the lower frequency band $350-450 \mathrm{~cm}^{-1}$ corresponds to the octahedral site. These typical bands in spinel structures are described in [14]. It is known that the difference in the vibration band position originated from the difference in the interval of cations located in the tetrahedral or octahedral sites.

Since the $\mathrm{Dy}^{3+}$ cation has an octahedral site preference over the $\mathrm{Fe}^{3+}$ cation, the reduction of the lattice constant originated from the replacement of the $\mathrm{Fe}^{3+}$ cation (ionic radius of $0.64 \AA$ ) by the $\mathrm{Dy}^{3+}$ cation (ionic radius of $0.99 \AA$ ) causes a decrease in the metal-oxygen bond length as [2]. The wave number peak of around $3500 \mathrm{~cm}^{-1}$ is due to the $-\mathrm{OH}$ stretching vibration of the absorbed water, while the peak centered at $1653 \mathrm{~cm}^{-1}$ is assigned to the $-\mathrm{OH}$ bending vibration of the absorbed water. The peaks at 1383 and $903 \mathrm{~cm}^{-1}$ are attributed to the stretching and bending vibration modes of the nitrate $\left(\mathrm{NO}_{3}^{-}\right)$group, the same as in [2]. The bands around $1400 \mathrm{~cm}^{-1}$ and $1600 \mathrm{~cm}^{-1}$ are assigned to

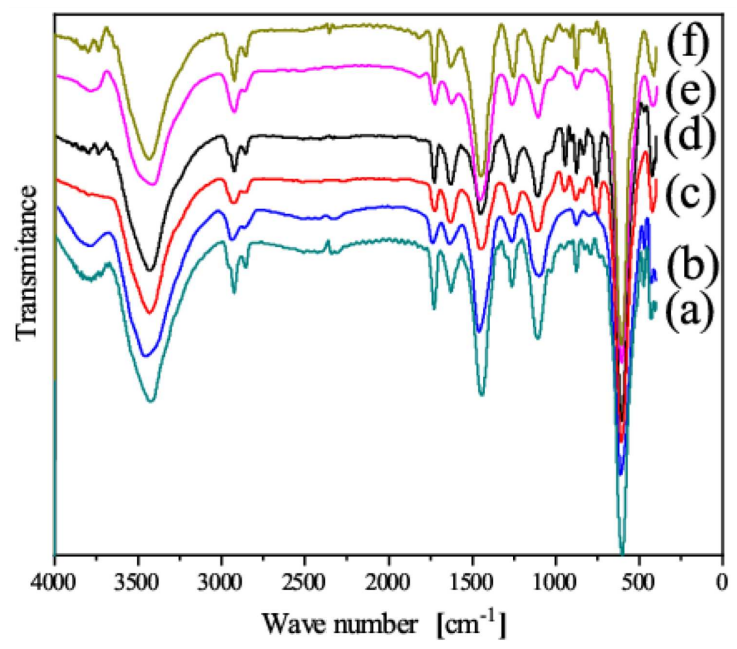

Fig. 2. FTIR spectra of $\mathrm{Ni}_{0.3} \mathrm{Co}_{0.7} \mathrm{Dy}_{x} \mathrm{Fe}_{2-x} \mathrm{O}_{4}$ nanoferrites, (a) $x=0$, (b) $x=0.02$, (c) $x=0.04$, (d) $x=0.06$, (e) $x=0.08$, and (f) $x=0.1$. 
the $\mathrm{C}-\mathrm{O}$ stretching vibration, the same as in [1]. The band around $600 \mathrm{~cm}^{-1}$ is attributed to the stretching vibration of $\mathrm{Fe}^{3+}-\mathrm{O}^{2-}$ in the tetrahedral complexes and the band around $400 \mathrm{~cm}^{-1}$ is due to that of octahedral complexes which correspond to [16].

\subsection{Field emission scanning electron microscopy analysis}

The structural morphology of the nanoparticles was investigated through FESEM micrographs. Figure 3 micrographs show the agglomerated grainy structure. It demonstrates that grain size increases with increasing the Dy content. FESEM images show that the $\mathrm{Ni}_{0.3} \mathrm{Co}_{0.7} \mathrm{Dy}_{x} \mathrm{Fe}_{2-x} \mathrm{O}_{4}$ nanoparticles prepared by the hydrothermal method have uniform spherical shaped grains. The micrographs show the agglomerated grain structure which is attributed to the interaction between magnetic nanoparticles, as mentioned in [7].

The estimated average sizes of the particles by ImageJ software were between 45 and $60 \mathrm{~nm}$. Therefore, increasing $\mathrm{Dy}^{+3}$ substitution leads to increasing the average particle size. It may be due to the placement of substitution cations at the grain boundaries, which causes the particles to connect to each other and increase their size. In addition, the nanoscale and the magnetic properties of the particles can lead to an increase in the degree of agglomeration of the prepared nanoferrites by increasing the $\mathrm{Dy}^{3+}$ substitution cation.

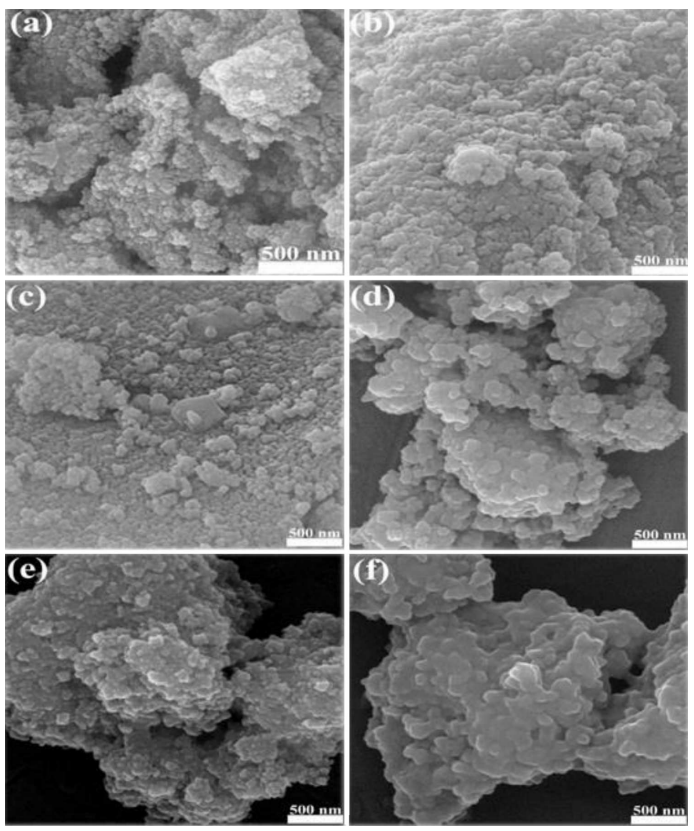

Fig. 3. The field emission scanning electron microscopy (FESEM) micrographs of the $\mathrm{Ni}_{0.3} \mathrm{Co}_{0.7} \mathrm{Dy}_{x} \mathrm{Fe}_{2-x} \mathrm{O}_{4}$ nanoferrite with composition of (a) $x=0$, (b) $x=0.02$, (c) $x=0.04$, (d) $x=0.06$, (e) $x=0.08$, and (f) $x=0.1$.

\subsection{EDS analysis}

In order to determine the elemental combination of nanosized particles, energy dispersive X-ray spectrometer patterns were carried out and shown in Fig. 4. Lines originating from the constituent atoms $\mathrm{Ni}, \mathrm{Co}, \mathrm{Fe}, \mathrm{Dy}$ and $\mathrm{O}$ which were recorded in the energy range of $0-10 \mathrm{keV}$ confirm the presence of $\mathrm{Co}, \mathrm{Ni}, \mathrm{Fe}, \mathrm{Dy}$, and oxygen elements. The measured values of composition must be regarded as a rough estimation due to the principal errors associated with the EDS method which varied up to $10 \%$ for oxygen and $5 \%$ for $\mathrm{Fe}, \mathrm{Ni}$, and Dy. The errors correspond to [11] errors. It is noted that the measured elemental ratios of compositions are in agreement with the stoichiometric formula. According to the EDX spectra, with the increase of Dy doped, the peak intensity of dysprosium increased, whereas the peak intensity for iron and nickel decreased. From the EDX spectra, it is clear that no additional impurities are present in the prepared samples. The peaks of substitution samples imply that cobalt and dysprosium ions enter in the ferrite structure.

\subsection{Magnetic properties}

The changes in magnetization as a function of applied magnetic fields for $\mathrm{Ni}_{0.3} \mathrm{Co}_{0.7} \mathrm{Dy}_{x} \mathrm{Fe}_{2-x} \mathrm{O}_{4}$ with Dy doping concentration $(x=0.0,0.02,0.04$, $0.06,0.08$, and 0.1 ) of ferrite samples were carried out by VSM at room temperature and the $M-H$ curves are shown in Figs. 5 and 6. The maximum applied magnetic field in our study was $10 \mathrm{kOe}$.

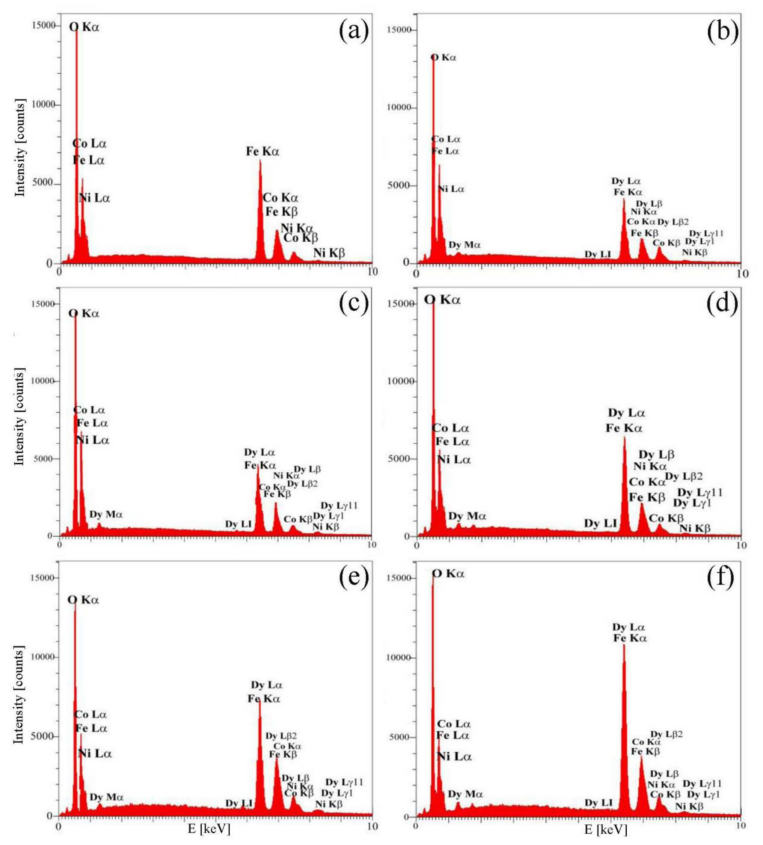

Fig. 4. Elemental composition and EDS patterns of $\mathrm{Ni}_{0.3} \mathrm{Co}_{0.7} \mathrm{Dy}_{x} \mathrm{Fe}_{2-x} \mathrm{O}_{4}$ with (a) $x=0$, (b) $x=0.02$, (c) $x=0.04$, (d) $x=0.06$, (e) $x=0.08$, and (f) $x=0.1$. 


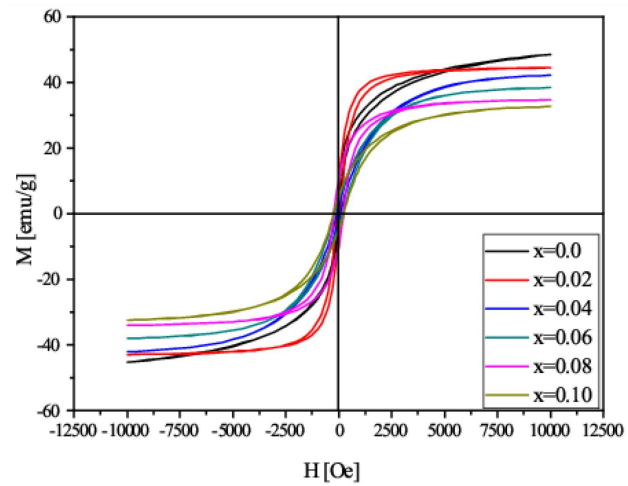

Fig. 5. Magnetic hysteresis loop of the investigated $\mathrm{Ni}_{0.3} \mathrm{Co}_{0.7} \mathrm{Dy}_{x} \mathrm{Fe}_{2-x} \mathrm{O}_{4}(x=0.0,0.02,0.04$, $0.06,0.08$, and 0.1 ) ferrite for maximum applied magnetic field $10 \mathrm{kOe}$.

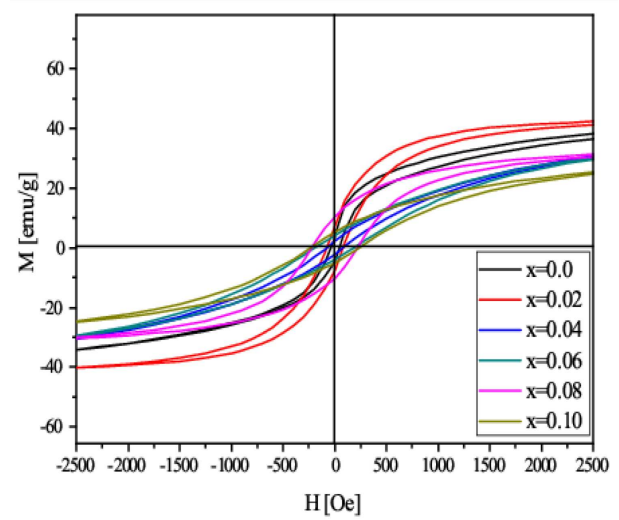

Fig. 6. Magnetic hysteresis loop of the investigated $\mathrm{Ni}_{0.3} \mathrm{Co}_{0.7} \mathrm{Dy}_{x} \mathrm{Fe}_{2-x} \mathrm{O}_{4}(x=0.0,0.02,0.04$, $0.06,0.08$, and 0.1 ) ferrite for maximum applied magnetic field $2.5 \mathrm{kOe}$.

The magnetic parameters vs coercivity $\left(H_{c}\right)$, saturation magnetization $\left(M_{s}\right)$ and remnant magnetization $\left(M_{r}\right)$ were determined from the $M-H$ curves and the values are tabulated in Table II. The sample's magnetic parameters show a significant dependence on the Dy content.

The saturation magnetization $M_{s}$ of the $\mathrm{Ni}_{0.3} \mathrm{Co}_{0.7} \mathrm{Dy}_{x} \mathrm{Fe}_{2-x} \mathrm{O}_{4}$ ferrite system decreases by increasing the Dy content. The height and width of the magnetic hysteresis loop are affected by several factors such as chemical combination, grain size, porosity, density, and sintering process, as mentioned in $[8,10]$. A soft ferromagnetic hysteresis behavior is seen for all shown compositions (as mentioned in [11]. The coercive field $\left(H_{c}\right)$ is small for all the present samples which predicts that they can be used in high density data storage devices [22]. The decrease in saturation magnetization is due to the maximum $\mathrm{Fe}^{3+}$ ion concentration on octahedral sites. It indicates the uniform decrease in saturation magnetization and remnant magnetization by $\mathrm{Dy}^{3+}$ ions substitution. This can be explained with the substitution of $\mathrm{Fe}^{3+}\left(5 \mu_{\mathrm{B}}\right)$ ions by $\mathrm{Dy}^{3+}$ ions which have a bigger magnetic moment $\left(10.5 \mu_{\mathrm{B}}\right)$.
TABLE II

Variation of coercivity $\left(H_{c}\right)$, saturation magnetization $\left(M_{s}\right)$ and remanence magnetization $\left(M_{r}\right)$ due to Dy doping concentration of $\mathrm{Ni}_{0.3} \mathrm{Co}_{0.7} \mathrm{Dy}_{x} \mathrm{Fe}_{2-x} \mathrm{O}_{4}$ samples.

\begin{tabular}{c|c|c|c}
\hline \hline Samples & $\begin{array}{c}H_{c} \\
{[\mathrm{Oe}]}\end{array}$ & $\begin{array}{c}M_{s} \\
{[\mathrm{emu} / \mathrm{g}]}\end{array}$ & $\begin{array}{c}M_{r} \\
{[\mathrm{emu} / \mathrm{g}]}\end{array}$ \\
\hline $\mathrm{Ni}_{0.3} \mathrm{Co}_{0.7} \mathrm{Fe}_{2} \mathrm{O}_{4}$ & 50 & 48 & 8 \\
$\mathrm{Ni}_{0.3} \mathrm{Co}_{0.7} \mathrm{Dy}_{0.02} \mathrm{Fe}_{1.98} \mathrm{O}_{4}$ & 65 & 44 & 6 \\
$\mathrm{Ni}_{0.3} \mathrm{Co}_{0.7} \mathrm{Dy}_{0.04} \mathrm{Fe}_{1.96} \mathrm{O}_{4}$ & 80 & 42 & 4 \\
$\mathrm{Ni}_{0.3} \mathrm{Co}_{0.7} \mathrm{Dy}_{0.06} \mathrm{Fe}_{1.94} \mathrm{O}_{4}$ & 188 & 38 & 3 \\
$\mathrm{Ni}_{0.3} \mathrm{Co}_{0.7} \mathrm{Dy}_{0.08} \mathrm{Fe}_{1.92} \mathrm{O}_{4}$ & 224 & 34 & 2 \\
$\mathrm{Ni}_{0.3} \mathrm{Co}_{0.7} \mathrm{Dy}_{0.10} \mathrm{Fe}_{1.90} \mathrm{O}_{4}$ & 248 & 32 & 2
\end{tabular}

Also, the magnitude of $H_{c}$ increased. Increasing paramagnetic Dy ions replace magnetic $\mathrm{Fe}^{3+}$ ions occupying the octahedral $\mathrm{B}$ sites which leads to a decrease of the magnetic moment in B sites. Clearly, this will result in the weakening of the super-exchange interaction between the A and B sublattices and a reduction in $\left(M_{s}\right)$. The results correspond to [2]. Also, as shown in Fig. 6, the coercivity has increased more regularly than the results of samples in [10]. The coercivity is influenced by such factors as magneto-crystalline anisotropy, micro-strain, magnetic particle morphology, size distribution, shape anisotropy and magnetic domain size. The increase in $H_{c}$ with Dy content $x$ can be understood as follows: The decrease in the crystallite size indicates the succeeding increase in porosity. Because of the demagnetizing field of pores, porosity affects the magnetization process. With increasing porosity, a higher field is needed to push the domain wall. When trivalent $\mathrm{Dy}^{3+}$ ions are substituted, they preferentially tend to occupy B sites.

\section{Conclusions}

The $\mathrm{Ni}_{0.3} \mathrm{Co}_{0.7} \mathrm{Dy}_{x} \mathrm{Fe}_{2-x} \mathrm{O}_{4}(x=0.0$ to 0.1$)$ ferrite samples are successfully synthesized by the simple and low-cost hydrothermal method. The crystal structure and phase recognition of all the prepared samples were determined using the XRD technique. The diffraction peaks of the samples show the existence of a single-phase spinel ferrite crystal structure with no traces of intermediate phases. In comparison to Fig. 2 of [21], the presence of the predominant cobalt ion in our compounds has eliminated the peak differences at [311] diffraction plan. The crystallite sizes and lattice parameters increased by increasing the Dy content. The FTIR spectra of the two characteristic peaks for the annealed samples, located at around $600 \mathrm{~cm}^{-1}$ and $450 \mathrm{~cm}^{-1}$, corresponding to the tetrahedral and octahedral sites, confirmed the formation of the spinel lattice. This result corresponds with the result of [21] qualitatively. In the present work, 
frequencies up to $4000 \mathrm{~cm}^{-1}$ have been used. In addition to minerals, the functional groups of organic matters in the compounds can also be identified.

The microstructural evolution results have shown that the synthesized $\mathrm{Ni}_{0.3} \mathrm{Co}_{0.7} \mathrm{Dy}_{x} \mathrm{Fe}_{2-x} \mathrm{O}_{4}$ has almost spherical structural morphology, with agglomeration of nanoparticles. The size of nanoparticles was found to be $45-60 \mathrm{~nm}$. The presence of magnetic nanoparticles and the high surface-to-volume ratio have led to more agglomeration in our compounds. The EDS analysis confirmed the presence of $\mathrm{Co}, \mathrm{Ni}, \mathrm{Fe}, \mathrm{Dy}$, and oxygen elements in the samples. Also, the measured elemental intensity of compositions is in agreement with the stoichiometric formula. Magnetization measurements showed that the $M_{s}$ and $H_{c}$ of nanoparticles change with $\mathrm{Dy}^{3+}$ substitution. In our constructed samples, the $M_{s}$ and $M_{r}$ decreased and $H_{c}$ increased significantly as the $\mathrm{Dy}^{3+}$ content increased.

In the samples [10, 20, 21], $H_{c}$ fluctuated. Saturation magnetization of samples [20,21] also occurred in $30 \mathrm{kOe}$. The hysteresis loops of our prepared samples are symmetric and saturated in a regular process, which is better than the results in [10]. The hysteresis loops in [10] showed visible noise between 2 and $10 \mathrm{kOe}$ which may depend on the preparation method. The uniform decrease in magnetization properties of our prepared samples and the uniform significant increased $H_{c}$ with the substitution of $\mathrm{Dy}^{3+}$ showed a soft ferromagnetic behavior and may be more suitable than the other samples for recording and storage.

\section{Acknowledgments}

The authors would like to thank the Yasouj University Research Council for financial support for this work [grant No. Gryu-89131110].

\section{References}

[1] M. Srivastava, S. Chaubey, A.K. Ojha, Mater. Chem. Phys. 118, 174 (2009).

[2] J. Feng, R. Xiong, L. Cheng, Y. Liu, J. Supercond. Nov. Magn. 30, 3513 (2017).

[3] J.-L. Ortiz-Quinonez, U. Pal, M.S. Villanueva, ACS Omega 3, 14986 (2018).

[4] M. Ristic, S. Krehula, M. Reissner, M. Jean, B. Hannoyer, S. Musić, J. Mol. Struct. 1140, 32 (2017).

[5] R.Z. Yarbay, H.E. Figen, S.Z. Baykara, Acta Phys. Pol. A 121, 44 (2012).
[6] M. Djamal, R. Khairurrijal, F. Haryanto, Acta Phys. Pol. A 128, B-19 (2015).

[7] M.K. Kokare, N.A. Jadhav, V. Singh, S.M. Rathod, Opt. Laser Technol. 112, 107 (2019).

[8] A. Nikzad, R. Parvizi, G. Rezaei, B. Vaseghi, R. Khordad, J. Electron. Mater. 47, 1302 (2018).

[9] L. Frolova, A. Derimova, T. Butyrina, Acta Phys. Pol. A 133, 1024 (2018).

[10] A.A. Kadam, S.S. Shinde, S.P. Yadav, P.S. Patil, K.Y. Rajpure, J. Magn. Magn. Mater. 329, 59 (2013).

[11] L. Chauhan, N. Singh, A. Dhar, H. Kumar, S. Kumar, K. Sreenivas, Ceram. Int. 43, 8378 (2017).

[12] M. Sertkol, Y. Koseoglu, A. Baykal, H. Kavas, A. Bozkurt, M.S. Toprak, J. Alloys Compd. 486, 325 (2009).

[13] D.H. Bobade, S.M. Rathod, M.L. Mane, Phys. B Condens. Matter 407, 3700 (2012).

[14] S.R. Kulal, S.S. Khetre, P.N. Jagdale, V.M. Gurame, D.P. Waghmode, G.B. Kolekar, S.R. Sabale, S.R. Bamane, Mater. Lett. 84, 169 (2012).

[15] I.H. Dunn, S.E. Jacobo, P.G. Bercoff, J. Alloys Compd. 691, 130 (2017).

[16] S.E. Shirsath, B.G. Toksha, R.H. Kadam, S.M. Patange, D.R. Mane, G.S. Jangam, A. Ghasemi, J. Phys. Chem. Solids 71, 1669 (2010).

[17] A. Ghasemi, M. Mousavinia, Ceram. Int. 40, 2825 (2014).

[18] R.S. Alam, M. Moradi, M. Rostami, H. Nikmanesh, R. Moayedi, Yang Bai, J. Magn. Magn. Mater. 381, 1 (2015).

[19] N.B. Velhal, N.D. Patil, A.R. Shelke, N.G. Deshpande, V.R. Puri, AIP Adv. 5, 097166 (2015).

[20] M.F. Warsi, A. Iftikhara, M.A. Yousuf, M.I. Sarwar, Sh. Yousaf, S. Haider, M.F.A. Aboud, I. Shakir, S. Zulfiqar, Ceram. Int. 46, 24194 (2020).

[21] A. Anwar, S. Zulfiqar, M.A. Yousuf, S.A. Ragab, M.A. Khan, I. Shakir, M.F. Warsi, J. Mater. Res. Technol. 9, 5313 (2020).

[22] M.A. Khan, M.J. Rehman, K. Mahmood, I. Ali, M.N. Akhtar, G. Murtaza, I. Shakir, M.F. Warsi, Ceram. Int. 41, 2286 (2015). 